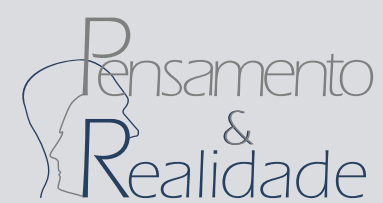

\title{
RELIGIÃO, SENTIDO E DOMINAÇÃO: UMA ORGANIZAÇÃO RELIGIOSA ANALISADA A PARTIR DA ABORDAGEM SOCIOLÓGICA WEBERIANA.
}

\author{
Ítalo da Silva ${ }^{1}$ \\ Jose Lindenberg Julião Xavier Filho ${ }^{2}$ \\ Elisabeth Cavalcante dos Santos ${ }^{3}$
}

Resumo

O objetivo deste artigo é entender as bases que sustentam o exercício da liderança nas relações sociais presentes numa organização religiosa a partir da abordagem sociológica weberiana, compreendendo a noção de liderança como um tipo singular de dominação. A pesquisa assumiu caráter qualitativo com realização de entrevistas semiestruturadas e análise documental numa igreja católica. Ao material empírico foi aplicado a técnica de análise de conteúdo. Como principais resultados, destacamos a existência de uma rede de sentidos subjetivamente visados entre o dominador e dominados, bem como a multiplicidade de sentidos para a ação social, demonstrando a complexidade explicativa do fenômeno da liderança. A contribuição para a área dos estudos organizacionais reside na busca por explorar a intersecção entre organizações e religião, tencionando o elo entre poder, relações sociais e dominação.

Palavras-chave: Sentidos da ação social; Dominação; Organização religiosa; Weber.

RELIGION, SENSE AND DOMINATION: A RELIGIOUS ORGANIZATION ANALYZED FROM THE WEBERIAN SOCIOLOGICAL APPROACH.

Abstract

The aim of this article is to understand the bases that support the exercise of domination in the social relations present in a religious organization from the Weberian sociological approach, understanding the notion of leadership as a unique type of domination. The research took a qualitative character with semi-structured interviews and documentary analysis in a catholic church. To the empirical material found through interviews and organizational documents, we apply content analysis. As main results, we highlight the historical reinforcement of organizational values through historicity and the existence of a network of subjectively targeted meanings connected between the dominator (leader) and his dominated (led). Our main contribution to the field of organizational studies is presented in the intention of exploring the intersection between organizations and religion, proposing the link between power, social relations and domination as central themes for debate in management research.

Keywords: Senses of social action; Domination; Religious organization; Weber.

1 - Universidade Federal de Pernambuco, Pernambuco, Brasil.

2 - Universidade Federal de Pernambuco, Pernambuco, Brasil.

3 - Universidade Federal de Pernambuco, Pernambuco, Brasil. 


\section{Introdução}

Questões sobre poder e liderança nas organizações (RAMOS et. al., 2016) muitas vezes podem ser compreendidas a partir das relações sociais (SILVA, 2015). Destas relações sociais é possível compreender as ações de ordem nas organizações permeadas por valores individuais e coletivos que garantem a permanência da dinâmica social a partir da manutenção de regras, normas, princípios regulatórios, crenças, ritos, universo simbólico e ideias, aos quais os agentes organizacionais estão inseridos (ALVES, 2004; FRIEDLAND, 2014; 2017; CENCI; FILIPPIM, 2017). A questão, portanto, que parece oportuna é entender como a dinâmica social é mantida numa esfera macro (sociedade) ou em contextos particulares, como nas organizações.

A dinâmica social envolve toda a sociedade, mas se mostra fortemente presente em alguns tipos particulares de organizações, como as organizações religiosas, que enfrentam o tempo mantendo uma dinâmica própria e sólida em termos de valores e liderança (DYCK; WIEBE, 2012). Se o argumento de Tracey (2012) de que os pesquisadores em administração recusaram-se envolver de maneira significativa com a religião e as formas religiosas de organização é válido, a bem da verdade, é válido também que sabemos pouco sobre a dinâmica dessas organizações religiosas seculares "e os valores e as práticas que as sustentam em processos sociais mais amplos" (TRACEY, 2012, p. 89).

No campo dos Estudos Organizacionais (EO), as organizações religiosas têm sido estudadas quanto ao fenômeno da empresarização do sagrado (GONÇALVES; SERRA; COSTA, 2007), ou as representações do lucro no comércio de artigos religiosos (ENOQUE; BORGES; BORGES, 2014; CORRÊA; VALE, 2017), ou ainda sobre a análise das relações entre as organizações religiosas e seus stakeholders (SERAFIM; ALPERSTEDT, 2012). Além das relações interpessoais na administração de pessoas a partir dos eclesiásticos (LIMA, 2016) e ainda a atração e permanência das pessoas aos contornos institucionais nestas organizações (CENCI; FILIPPIM, 2017). Esses estudos exemplificam a multiplicidade de desenhos de pesquisa envolvendo organizações religiosas como objeto epistêmico, atestando a relevância desse objeto de investigação para a compreensão da dinâmica social.

Assim, sabemos pouco como as questões sobre poder, autoridade e liderança se dão dentro das organizações religiosas mediante as relações entre os agentes organizacionais (DYCK; WIEBE, 2012; SILVA, 2015), e essa é uma lacuna que vem continuamente sendo provocada pelos críticos sobre o caminho que a ciência da administração percorreu nas últimas décadas, ou seja, se afastando do ambiente performático próprio dos agentes organizacionais (SOUZA et al., 2018). Por agentes organizacionais compreendemos tanto os indivíduos que exercem a liderança quanto aqueles que estão subordinados a ela dentro da organização e que são capazes de transformar as relações organizacionais através da ação, reação e interação coletiva (ALVES, 2004).

Desse modo, pesquisas com essa inclinação se desenvolvem a partir dos agentes organizacionais que se relacionam, promovem ações e formulam hábitos dentro de uma organização - neste caso religiosa, imersos nas relações de dominação como exercício de liderança organizacional na busca de ponderar tanto o lado de quem lidera e institui seu mando, quanto o lado de quem está sendo liderado, dominado, por assim dizer, suscetível de comando. Por consequência, é na relação e não nos agentes que a atenção deve ser depositada, pois a relação se mantém, tem conotações estruturais, de modo que vai além dos 
agentes (SILVA; CARVALHO, 2020).

Se falta, como afirma Tracey (2012), aos pesquisadores de organizações explorar a intersecção entre organização e religião no campo dos EO, então recorremos a teoria weberiana de sentidos de ação social e os tipos ideais de dominações (ARONOVITCH, 2012; WEBER, 2015) para entender a liderança como relação social entre agentes com interesses organizacionais delimitados (SILVA, 2015; LIZARDO; STOLTZ, 2017; SILVA; CARVALHO, 2020). Schiermer (2016) argumenta que por trás das ações sociais há agentes inseridos em contextos sociais e culturais que podem ser apreendidos nas organizações. Sendo essas organizações religiosas, por sua vez, as representações coletivas com respaldo nas posições dos agentes que permite compreender a ordem organizacional, as relações de poder, as crenças religiosas e as esferas de valores/sentidos individuais e coletivas (FRIEDLAND, 2014; 2017).

A discussão até aqui oportunizada define o ponto de vista a partir do qual se observa a dinâmica social nas organizações religiosas, de modo que essa pesquisa examina os sentidos individuais e partilhados que caracterizam os modos de dominação existentes nas relações entre agentes numa organização religiosa com forte atuação social (liderança destacada). O líder religioso local (padre), e os demais agentes organizacionais, compõem o quadro de relações a ser estudado mediante o objetivo principal da pesquisa, qual seja, entender as bases que sustentam o exercício da dominação nas relações sociais presentes numa organização religiosa a partir da abordagem sociológica weberiana

Esse objetivo ressalta ao apelo de Silva e Carvalho (2020) que é necessário estudar as de dominação em outros possíveis campos de ação de líderes e liderados, com foco no relacionamento social e na reprodução intencional de regras de conduta. Assim, o pressu- posto que oriente essa pesquisa percebe a liderança como um tipo singular de dominação no sentido weberiano, exercido em relações sociais compreendidas mediante os sentidos individuais e coletivos dos agentes dentro das organizações (SILVA, 2015; WEBER, 2015). Acreditamos que nesta pesquisa, a nossa contribuição para a área dos estudos organizacionais reside na busca de explorar intersecção entre organizações e religião, tencionando o elo entre poder, relações sociais e dominação como temáticas centrais de debate no campo de pesquisa da ciência da administração influenciadas pelo pensamento weberiano (DYCK; WIEBE, 2012; TRACEY, 2012).

\section{A Relação entre Sentido, Ação Social e Dominação na Perspectiva Weberiana}

Ao observar bem, esta pesquisa oferece uma análise a partir dos indivíduos como unidade básica social de estudo. Concordamos com Silva (2015) que é importante entender a ideia de dominação como exercício da liderança nas relações sociais que leva em consideração os sentidos/valores subjetivos dos agentes organizacionais. Afinal de contas, como nos alerta Weber (2000), a liderança é exercida e sua presença se percebe a partir do dominado/liderado, de modo que as bases da dominação/liderança são indiretamente acessadas. Ou seja, não é perguntando ao líder porque os liderados os seguem, mas sim o inverso, perguntando aos dominados/liderados quais as bases de sua ação. É o reforço do indivíduo como sujeito epistemológico o cerne deste posicionamento, buscando as razões que sustentam a ação (WEBER, 2015).

Assim, Weber (2015) explica que, no indivíduo, o sentido é subjetivamente visado num tipo puro conceitual, construído pelo agente ou pelos agentes concebidos como típicos. E desse conceito de sentido é prudente destrinchar três pontos de análise fundamentais, a que o próprio Weber (2015) chamou de 
teoria da ação social. Um primeiro ponto é que o sentido atribuído pelo indivíduo ao seu comportamento possui caráter de subjetividade e difere de indivíduo para indivíduo, uma vez que decorrem de anseios e necessidades de diferentes pertencimentos sociais para cada um enquanto agente social e organizacional.

Um segundo ponto é que, não necessariamente, o(s) comportamento(s) estipulado(s) pelos indivíduos estão orientados por um único sentido. Isto é, uma ação social não é guiada exclusivamente por uma unilateralidade de significado. Dito de outra forma, as bases racionais para a ação são múltiplas e coexistentes, gerando uma complexidade causal de sentidos em cada ação, visto que nada impede que uma ação social esteja carregada de inúmeros sentidos, percepções e significados. Podendo assim ser, e comumente é, um comportamento guiado uni ou multilateralmente enquanto sentido concedido pelo indivíduo. Dessa forma, ao menos dois tipos de racionalidade estão presentes, como bem aponta Weber (2015), a racionalidade formal instrumental, que versa acerca da adequação meio-fim, e a racionalidade valorativa substancial, que versa acerca de um modo distinto da adequação meio-fim, dando vazão a valores, crenças e, no limite, a aspectos subjetivos (THIRY-CHERGUES, 2009).

Um terceiro ponto é que não nos cabe atribuir um julgamento de valor ao(s) sentido(s) que o(s) indivíduo(s) coloca(m) em seu(s) comportamento(s) social(is), porque assim quebraria com a lógica da subjetividade e reduziria o entendimento da sociedade ou das organizações a uma discussão antidialética, ou ainda mais distante do entendimento de Weber (2015), a um julgamento estrutural, de cima para baixo. Para ficar mais claro, dizemos que o sentido de uma ação social possui característica de subjetividade, uni ou multilateralidade de sentidos e de negação de um possível julgamento de valor a priori ou fora do indivíduo que age. Portanto, olhar a partir do indivíduo é condição sine qua non para compreender a dinâmica social e as bases para as ações que os agentes executam, em particular nesta pesquisa - as bases para compreender a dominação enquanto exercício da liderança organizacional (SILVA, 2015).

Para Friedland (2014), os sentidos podem ser compreendidos mediante esferas de valores que influenciam o comportamento dos agentes nas organizações. Assim, a partir das posições ocupadas por esses agentes dentro das organizações é possível perceber a ordem organizacional existente, as relações de poder, a representação coletiva, os meios e fins das ações dos agentes e o organizar simbólico da liderança organizacional (FRIEDLAND, 2014; 2017). Tais sentidos/valores dos agentes, quando compartilhados, formulam doutrinas, religiões, crenças em coerência lógica individual que é também coletiva (FRIEDLAND, 2014; ZAFIROVSKI, 2013), produzindo um amálgama explicativo que toca no indivíduo, mas o transcende para o coletivo imediato no contexto da organização.

Dessa maneira, ao se formar as interações organizacionais - entendidas como comportamentos compartilhados (quanto ao sentido) e percebidos (quanto a ação) por mais de um agente - entre o dominador e seus dominados existe um sentido de ação forte que legitima o controle e comando exercido nas organizações através do sistema de poder e sujeição interna (THIRY-CHERGUES, 2009; SILVA; CARVALHO, 2012; WEBER, 2015). Sendo assim, dominação é a probabilidade que um agente tem de encontrar obediência entre outros agentes nas relações sociais. A legitimidade da dominação é instituída através do(s) indivíduos(s) dominado(s) (WEBER, 2015), razão pela qual a explicação da dominação não está no dominante, mas no elenco teleológico ativado pelos dominados. 
Assim, Silva e Carvalho (2020) afirmam que as relações sociais podem ser orientadas por ordens legítimas entre líder-liderados, garantido a validade das ações. Esse entendimento relacionar-se com os tipos ideais de dominação que explicaremos a seguir, e faz com que a legitimidade em uma relação social possa ser compreendida de maneira afetiva ou racional aos valores/sentidos religiosos, bem como pelas expectativas e consequências de interesses entre os agentes por convenção ou lei com sentidos mais amplos e compartilhados (FRIEDLAND, 2014; SILVA; CARVALHO, 2020).

Como afirma Silva (2015), é possível entender a liderança a partir da subjetividade dos agentes envolvidos nas relações sociais que constituem valores individuais e partilhados dentro das organizações, caracterizando seus comportamentos nas relações de poder (SCHIERMER, 2016; FRIEDLAND, 2014; 2017). Logo, "liderança é um tipo singular de dominação, no sentido weberiano, exercido em relações sociais" (SILVA, 2015, p. 27), por isso tratamos de dominação como um exercício particular de liderança nesta pesquisa a partir da abordagem sociológica weberiana, mesmo sabendo que possuem, a depender do campo epistemológico de partida, sentidos diferentes. As bases conceituais acerca dos tipos puros de dominações weberianas legitimadas são cruciais para entender as relações interpessoais interessadas nas organizações (ARONOVITCH, 2012; LIZARDO; STOLTZ, 2017).

Quando o caráter em que se assenta a dominação é a tradição, Weber (2015) entende que nesse tipo de dominação os costumes tornam-se certos e inquestionáveis e, pela repetição, são passados de geração em geração instituindo assim valores sociais e criando papéis de comportamento que influenciam as relações dos agentes dentro das organizações (ALVES, 2004). Tais agentes veem na tradi- ção: segurança e confiança - e elevam esses sentimentos para os motivos que servem de base para o exercício da liderança (WEBER, 2015). A esse tipo de motivação para a ação (dominação), Weber (2015) chama de dominação tradicional.

Quando o caráter da dominação é legal, ou seja, ancorado em pressupostos positivados, Weber (2015) a chama de dominação racional-legal. Quem detém a possibilidade de exercer a dominação racional-legal a exerce porque foi designado para o posto, dentro da legalidade e em união com seus dominados instituem regras e estatuto de conduta. Os costumes não são verdades absolutas e por vezes são ignorados e/ou mudados pelos agentes que criam e recriam a realidade em que se encontram (WEBER, 2015), razão da principal diferença entre este tipo de dominação e a dominação tradicional.

Já quando o caráter da dominação é o carisma, Weber (2015) denomina de dominação carismática. Neste tipo puro de dominação o comportamento do dominador - aos olhos do dominado - diz muito sobre ele e se torna fundamental porque se espera que exista um consenso de modos de agir por parte do dominador e por parte dos dominados. Ressaltamos que a dominação carismática não excluí a necessidade de se ter um ordenamento organizacional estabelecido. Pelo contrário, a dominação carismática apresenta "uma forma estrutural social claramente definida, com órgãos pessoais e um aparato de serviços e bens materiais que se adaptam à missão do portador do carisma" (SILVA; CARVALHO, 2012, p. 30). Ao longo do tempo, a dominação carismática se assenta em bases de tradição, caí na rotinização, viram-se dogmas, regras e ordenamentos jurídicos, estatutos de condutas (SILVA; CARVALHO, 2012). Pode-se pensar em uma sequência do carisma para outro tipo de dominação, embora não necessariamente, mas a dominação carismática é a que reco- 
nhece no carisma do dominador a razão para a própria dominação.

Nesse ponto, o nosso argumento é que a compreensão dos sentidos a partir do agente organizacional possibilita melhor entender as relações organizacionais aos quais os agentes estão inseridos. Tais relações no âmbito das organizações estão permeadas por esses sentidos/valores que implicam no exercício de liderança pelos agentes (FRIEDLAND, 2014; SILVA, 2015). Portanto, através dos sentidos individualmente atribuídos às ações é possível compreender as esferas de valores coletivas que sustentam o exercício da liderança e, por consequência, os valores internalizados nos comportamentos dos agentes que são politizados, por vezes, (ir)racionais, inteligíveis, representacionais, significativos (coletivamente). Tais comportamentos ou ações apresentam também poder, influência e lógica interna de ordenação nas organizações (FRIEDLAND, 2014; 2017).

Os três tipos de dominação weberiana aqui conceituadas são entendidos como tipos ideais puros que são usados como forma de compreender as diferentes realidades sociais e organizacionais. Para Aronovitch (2012), os tipos ideais weberianos precisam ser aproximados da realidade empírica, não devem ser entendidos como algo totalmente puro e racionais, e estão abertos às transformações sociais pelos agentes. Desta maneira, compreendemos que a realidade organizacional é multifacetada, complexa e híbrida, apresentando características peculiares que atravessam os conceitos-chave de dominação weberiana e legitimam seu exercício mediante as relações de ordem organizacionais inscritas em certo tempo e local, por agentes específicos.

Assim, a base teórica com a qual se observa o exercício da liderança nesta pesquisa reverte-se do olhar weberiano da dominação e, como assentamento teórico, consideramos três tipos-puros de dominação como aproxi- mação ao fenômeno da dominação na organização religiosa objeto da pesquisa: Tradicional, Racional-legal e Carismática. Além disso, como já discutido, é indispensável reconhecer que tanto o agente dominador quanto os dominados precisam integrar o desenho como indivíduos epistemológicos.

\section{Procedimentos Metodológicos}

Neste estudo buscamos entender as bases que sustentam o exercício da liderança como um tipo singular de dominação nas relações sociais presentes numa organização religiosa a partir da abordagem sociológica weberiana. Adotamos a natureza de pesquisa qualitativa com base na realização de entrevistas semiestruturadas e análise documental (MERRIAM, 2009). Na pretensão de atribuir validade e confiabilidade a pesquisa, utilizamos como fontes de análise empírica as entrevistas, como fonte primária, e os documentos como fontes secundárias (BAUER, 2002; CRESWELL; MILLER, 2010; PAIVA; LEÃO; MELLO, 2011).

A dinâmica social de dominação a ser estudada e os agentes imersos nela envolvem uma Igreja Católica, instaurada desde de 1932 na região do agreste de Pernambuco, e que conta com atuação histórica no município em que está localizada e nos municípios circunvizinhos, além de contar com um líder religioso (Padre) com notório destaque em termos de liderança noticiados em veículos de comunicação local e em documentos internos próprios da organização católica (ARAUTOS DO EVANGELHO, 2004; AVENTURA PASSIRA, 2012; DIÁRIO POLÍTICO, 2013). Tal líder religioso vem conseguindo promover a construção de obras como a igreja matriz central da cidade, além de capelas e centros de catequeses nas comunidades da zona rural cativando as doações dos fiéis e promoções de eventos religiosos. 


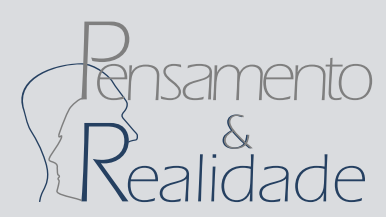

Dessa maneira, o padre - aqui tratado como um líder/dominador - foi o primeiro a ser entrevistado de um total de seis entrevistas realizadas. $\mathrm{O}$ número de entrevistas foi limitado pelo acesso dos pesquisadores aos sujeitos em campo. A entrevista foi realizada no Casa Paroquial (a residência oficial do padre), em 12/10/2017 e durou, aproximadamente, quarenta e seis minutos, com gravação autorizada. As questões semiestruturadas do roteiro de entrevistas eram voltados para o mapeamento dos grupos organizacionais que atuam na paróquia e seus coordenadores. $\mathrm{O}$ motivo foi mapear os grupos organizacionais

com os quais o padre se relaciona e verificar nos dominados as bases para o exercício da liderança.

Assim, realizamos também uma entrevista com a secretária paroquial em 21/10/2017 na sacristia da igreja, o que possibilitou detalhar os grupos organizacionais de atuação central na organização. A tabela 1 é resultado do mapeamento dos grupos organizacionais atuantes na paróquia, bem como a relação dos grupos acessados, o código de identificação dos entrevistados da pesquisa, as formas de acesso, e as datas em que as fontes foram acessadas e quando as entrevistas foram realizadas.

Tabela 1. Mapeamento das pastorais e movimentos religiosos da lgreja.

\begin{tabular}{|c|c|c|c|c|}
\hline $\begin{array}{l}\text { Pastorais e } \\
\text { Movimentos } \\
\text { Religiosos Mapeados }\end{array}$ & $\begin{array}{l}\text { Pastorais e } \\
\text { Movimentos } \\
\text { Religiosos } \\
\text { Acessados } \\
\end{array}$ & $\begin{array}{l}\text { Código de } \\
\text { identificação } \\
\text { dos } \\
\text { entrevistados: }\end{array}$ & $\begin{array}{l}\text { Formas de } \\
\text { Acesso: }\end{array}$ & $\begin{array}{l}\text { Fontes } \\
\text { Acessadas } \\
\text { em: }\end{array}$ \\
\hline Casa Paroquial & Sim & Padre & Entrevista & $12 / 10 / 2017$ \\
\hline Secretária Paroquial & Sim & E1 & Entrevista & $21 / 10 / 2017$ \\
\hline Pastoral da Família & Sim & - & Documentos & $29 / 10 / 2019$ \\
\hline Pastoral da Criança & Sim & - & Documentos & $29 / 10 / 2019$ \\
\hline Pastoral da Liturgia & Sim & E2 & $\begin{array}{l}\text { Entrevista e } \\
\text { documentos }\end{array}$ & $\begin{array}{l}21 \mathrm{e} \\
29 / 10 / 2019\end{array}$ \\
\hline Pastoral da Juventude & Sim & E3 & $\begin{array}{l}\text { Entrevista e } \\
\text { documentos }\end{array}$ & $\begin{array}{l}10 \mathrm{e} \\
29 / 10 / 2019\end{array}$ \\
\hline Pastoral da Catequese & Sim & E4 & $\begin{array}{l}\text { Entrevistas e } \\
\text { documentos }\end{array}$ & $\begin{array}{l}29 \mathrm{e} \\
30 / 10 / 2019\end{array}$ \\
\hline $\begin{array}{l}\text { Pastoral da } \\
\text { Comunicação }\end{array}$ & Sim & E5 & $\begin{array}{l}\text { Entrevista e } \\
\text { documentos }\end{array}$ & $\begin{array}{l}28 \mathrm{e} \\
29 / 10 / 2019\end{array}$ \\
\hline Apostolado da Oração & Sim & - & Documentos & $29 / 10 / 2019$ \\
\hline Grupo de Coroinhas & Não & - & - & - \\
\hline $\begin{array}{l}\text { Encontro de Casais em } \\
\text { Cristo (ECC) }\end{array}$ & Sim & - & Documentos & $29 / 10 / 2019$ \\
\hline $\begin{array}{l}\text { Ministros da } \\
\text { Comunhão }\end{array}$ & Não & - & - & - \\
\hline $\begin{array}{l}\text { Movimento Treinamento } \\
\text { de Liderança Cristã } \\
\text { (TLC) }\end{array}$ & Sim & E2 & Entrevista & $\begin{array}{l}21 \mathrm{e} \\
29 / 10 / 2019\end{array}$ \\
\hline $\begin{array}{l}\text { Renovação Carismática } \\
\text { Católica (RCC) }\end{array}$ & Não & - & - & - \\
\hline Oficina de Oração & Sim & - & Documentos & $29 / 10 / 2019$ \\
\hline Terço dos Homens & Sim & - & Documentos & $29 / 10 / 2019$ \\
\hline
\end{tabular}

Fonte: elaborada pelos Autores (2020). 
As pastorais são grupos que contêm atividades específicas desenvolvidas pela paróquia com caráter mais permanente. Os movimentos e demais grupos religiosos também exercem atividades religiosas temáticas com caráter mais ligado às figuras religiosas responsáveis pela fundação de tais grupos e movimentos a nível de organização nacional da Igreja Católica. Assim, foram realizadas mais quatro entrevistas com os coordenadores das pastorais da juventude (E4), liturgia (E3), comunicação (E6), e catequese e crisma (E5). Um dos coordenadores entrevistados coordenava tanto a pastoral da liturgia como o movimento de "treinamento e liderança cristã" (TLC). Do total de seis entrevistados, quatro foram do sexo masculino e dois do sexo feminino.

As entrevistas ocorreram no centro de catequese, na igreja matriz da cidade e na casa dos entrevistados. A escolha por entrevistar os coordenadores baseou-se na dupla vinculação deles com o fenômeno da dominação/liderança, pois tem contado direto e constante com o padre e com os indivíduos de seus grupos organizacionais. As seis pessoas entrevistadas foram as que possuíam fácil acesso e se disponibilizaram voluntariamente para receber os pesquisadores. Todas as entrevistas foram gravadas com autorização e, posteriormente, transcritas.

A realização das entrevistas contou com um pesquisador, e este mesmo pesquisador colheu as seis entrevistas. Um cuidado especial foi empregado para validar as interpretações na sequência das entrevistas, pois, como Flick (2012) observa, na pesquisa qualitativa a fase de coleta e interpretação de material mantém uma constante interdependência constitutiva. Assim, a triangulação de pesquisadores também foi empregada, como argumentam Paiva Junior, Leão e Mello (2011), sendo um procedimento que tanto reforça a validade quanto a confiabilidade da pesquisa qualitativa. A cada entrevista uma rodada de conversa entre os pesquisadores foi realizada a fim de validar intersubjetivamente os achados e impressões.

A análise documental consistiu no exame de documentos escritos do acervo institucional da organização. Foram analisados seis documentos escritos: (1) calendário anual das atividades da Pastoral da Comunicação; (2) calendário de atividades do movimento TLC; (3) calendário de atividades da pastoral da catequese e grupo de oração sal e luz; (4) calendário de atividades da pastoral da criança e do dízimo; (5) calendário de atividades da pastoral da família e encontro dos casais em cristo; e (6) calendário de atividades do apostolado da oração e terço dos homens. Os documentos traziam detalhes, por exemplo, sobre quais atividades eram desenvolvidas, qual o evangelho (trecho da bíblia) e santo católico estavam associados às atividades e os temas tratados por cada atividade realizada, bem como identificava o líder do grupo como remetente das mensagens.

A técnica analítica empregada foi a análise de conteúdo (BAUER, 2002). A categoria de análise central consistiu no entendimento da liderança como um tipo singular de dominação, no sentido weberiano, exercido em relações sociais permeadas por diversos sentidos/valores representados nas subcategorias temáticas (FRIEDLAND, 2014; SILVA, 2015). As subcategorias temáticas foram orientadas mediante: (1) a subcategoria dos sentidos/valores das ações sociais dos agentes; (2) a subcategoria da dominação tradicional e os sentidos/valores associados; (3) a subcategoria da dominação racional-legal e sentidos/valores associados; e (4) a subcategoria da dominação carismática e sentidos/ valores associados. A partir disso, aproximamos os trechos das falas dos entrevistados e os trechos retirados dos documentos escritos para constituir o entendimento por trás dos sentidos individuais e partilhados que servem 
de base para o exercício da liderança organizacional.

\section{Resultados e Discussão}

Com o objetivo de entender as bases que sustentam o exercício da liderança como um tipo singular de dominação nas relações sociais presentes na organização religiosa aqui estudada, organizamos os principais resultados e a discussão em duas subseções, a começar pela subseção que apresenta uma discussão sobre os sentidos dos agentes organizacionais e depois uma outra subseção que aponta a hibridez dos tipos de dominação.

\subsection{O Sentido como Orientador da Ação Social: O Padre e Os Adeptos}

O padre como sujeito que dissemina "os sinais do Espírito Santo na vida das pessoas e na história" (CNBB, 2008, p. 51) e também está na "alegria de ser discípulo missionário" (CNBB, 2008, p. 52) relatou ter vivido uma adolescência muito árdua, mas que sempre carregou consigo a vontade de estudar e assim transformar a realidade de vida em que se encontrava. O trecho a seguir da entrevista realizada com o padre retrata essa aspiração.

Quando foi um certo dia um colega meu estudava né, me perguntou se eu não queria estudar. Eu disse: "como eu vou poder estudar se eu não tenho condições?". Aí ele disse, eu te levo e apresento ao padre [do seminário] vai ser padre, eu disse: "ser padre? Eu quero ser padre não". E nessa época [...] eu tinha quinze anos [...] aí eu fui falar com o padre [do seminário] com ele. Aí o padre [do seminário] perguntou: "você quer ser padre?". Eu disse: "não...". [Padre do seminário:] "quer o quê?" Eu quero estudar. Ele perguntou para mim: "mas o que você sabe fazer?" Sei trabalhar. Aí ele me disse que eu ia trabalhar no seminário né e ia ter direito a estudar sem ganhar nada né, sem ser remunerado, só pra estudar (Padre).
Diante das dificuldades financeiras e a vontade de estudar, os sentidos de ação social do padre foram sendo construídos desde a mais tenra idade se pautando na crença do trabalho duro. Embora, de início, nunca foi uma vontade do padre seguir o ofício do sacerdócio, entendemos que a vivência no seminário influenciou e permitiu instituir os sentidos cruciais na composição de sua identidade pessoal e profissional. "A coragem de trabalhar e a fé. Eu sempre trabalhei muito né. Nunca renunciei trabalho [...] também tenho consciência das minhas negligências, dos meus pecados, eu sou humano né, faz oito anos aqui [na atual paróquia] que a gente trabalha" (Padre), indicando que o trabalho é um traço central de sua identidade mesmo antes do sacerdócio.

Através do trabalho duro, o padre instituiu construções de médios e grandes portes ligada à sua atuação na Igreja Católica: "Eu faço mais como padre, eu acredito... eu acredito não, eu faço. E mesmo que eu gosto de construir. Em todo canto que eu passei eu fui edificando [...] eu já gosto de construir, eu tenho minhas construções, eu tenho esse trabalho na paróquia". O padre sempre construiu paróquias com arquiteturas grandiosas, capelas, centros de estudos catequéticos, entre outras edificações, pelas paróquias que já passou: "Em todo canto que eu passei eu fui edificando as coisas [...] porque a minha vinda a Passira assim... foi por causa da construção da matriz nova, porque o bispo, Dom Severino, ele me convidou pra vir porque sabendo que eu gosto de construção". Deste modo, compreendemos que o comportamento de ação do padre possui sentidos pautados na crença da fé e na força de construir (espiritual e/ou fisicamente), isto é, valores que reforçam o significado de atuação individual enquanto líder religioso (FRIEDLAND, 2014; WEBER, 2015).

Resgatando um pouco a biografia do padre, é possível perceber o forte sentido que 
ele carrega da crença na fé cristã e na vontade de edificar os preceitos religiosos. Como o próprio padre relata:

Eu passei, a minha primeira experiência de trabalho foi em Itambé, passei seis meses e eu atendia só nos finais de semana e, mas nesse intervalo que eu passei... eu fiquei no seminário acompanhado os seminaristas e eu ficava em Olinda. Fiquei um ano aliás em Feira Nova e passei seis meses em Nazaré e aí os outros seis meses eu passei em Olinda, em Itambé. E em 1989 eu vim trabalhar em, em... fui transferido do seminário pra a paróquia de nossa... de Santa Ana em Vicência, aí eu passei seis anos e meio [...] eu faço mais como padre que como psicólogo [estudou psicologia enquanto estava em Vicência], eu acredito... eu acredito não, eu faço. E mesmo que eu gosto de construir. Em todo canto que eu passei eu fui edificando as coisas e não me sobra tempo não [...] É... construí... terminamos o centro de catequese deixado pelo padre [anterior a ele], conclui que hoje já rende uma renda extra pra paróquia e aqui [casa paroquial] fizemos alguns reparos, recuperamos a igrejinha de Pedra Tapada. Terminamos também a igreja em Vajada. Estamos concluindo a igreja, a capela, a reforma em Bengalas e também em Candiais, Poço do Pau, mas a paróquia é muito extensa, tem muita coisa e a gente não abarca e quanto mais que comecei a construir... porque a minha vinda a Passira não foi tanto, assim... foi por causa da construção da Matriz nova, porque o bispo que estava naquele tempo, a nove... oito anos passados, dom Severino, ele me convidou pra vir porque sabendo que eu gosto de construção (Padre).

A partir desse relato, entendemos que a competência de edificar (mundana e imanente aos homens) reforça uma áurea vocacional (espiritual) que, neste sentido, reforça a crença da fé. Existem, portanto, um recurso de reforço mútuo já percebido por Weber (1996; 2015), situação em que valores ou sentidos espirituais reforçam condutas e ações mundanas (tanto dominador, como dominados) em um círculo virtuoso que se consolida com mútuo reforço, fortalecendo ainda mais a ação (HOUGNTON, 2010; FRIEDLAND, 2014; 2017). Os sentidos valorativos percebidos no padre fazem com que se conceba uma percepção positiva dele diante dos agentes organizacionais. Como é possível perceber nos relatos abaixo:

Ele tem importância muito grande por quê? Porque... por dois aspectos que eu vejo o padre, primeiro porque ele é o meu líder e o líder da igreja [...] é como a gente diz "ele é o bom pastor", é ele que me guia, certo? E a nível, vamos dizer assim, pessoal, ele é um amigo pra mim, ele é muito próximo tanto de mim, quanto da minha esposa, da minha família. Então, eu vejo ele como uma pessoa não só como um amigo né? Ele é meu amigo, mas também ele é o meu pastor. É ele que me guia. Ele é meu pastor. Eu devo a ele no mínimo satisfação, orientação, eu tenho que rezar por ele, eu tenho que caminhar junto com ele (E3).

Rapaz... extrema. A importância dele [o padre] é extrema [...] como pastor ele é bem incisivo no que quer, ele não manda recado, ele chega e diz: "olha, eu quero isso dessa maneira, dessa e dessa vamos fazer?", então a gente se reúne e faz. Ele é a pessoa que tem sido um alicerce [...] Ele chegou em Passira há oito anos atrás, e aos poucos ele conseguiu ir conquistando os paroquianos pela maneira de ser, de atuar. Por ser sincero, por ser verdadeiro, por ser honesto, muito honesto, a gente vê tudo que ele pega [recursos financeiros] pra onde vai, pra onde foi, entendesse?" (E5).

Em outras palavras, os sentidos que o 


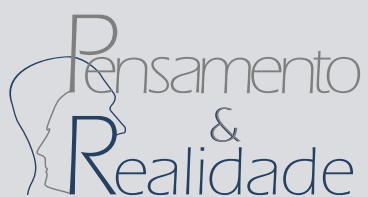

padre carrega corroboram como ponto de referência na orientação e controle da ação dos agentes organizacionais a ele subordinado, o que possibilitou o nosso entendimento sobre a base de exercício da dominação organizacional, uma vez que a relação líder e liderado(s), ou ainda, nos termos weberianos, dominador e dominado(s), fornece um ponto focal para compreendermos o comportamento do padre através dos sentidos subjetivamente visados por outros agentes organizacionais, estimulando assim as dinâmicas das relações interpessoais na organização com a criação de valores coletivos (FRIEDLAND, 2014; SILVA, 2015).

Quando olhamos para os agentes organizacionais subordinados ao padre que atuam nas pastorais, os sentidos que guiam suas ações sociais estão sustentados em crenças compartilhadas (valores adquiridos pela participação nos grupos organizacionais e a crença no misticismo religioso católico). Essas crenças, por vezes, são racionalmente compreensíveis a ponto de a entendermos como sentido social resultante da inserção dos agentes nas práticas religiosas existentes. No entanto, por vezes, essas crenças são constituídas sem uma sequência lógica puramente racional, isto é, guarda respaldo no místico religioso e transcendental, sendo um exemplo claro do que Weber (2015) denomina de múltiplas racionalidades sustentando a ação social.

E aí pra mim, vamos dizer assim, isso serviu bastante porque me aproxima, me conseguiu aproximar mais da igreja, já quando eu tinha uma certa prática religiosa $[\ldots]$ mas a contribuição que o grupo tem pra mim é essa, me ensinou a caminhar na igreja e me ensinou a lidar [...] com outras pessoas (E1).

$\mathrm{Na}$ verdade, assim, não tem uma razão lógica. É... a gente quando... é um chamado de Deus pra tá a frente, pra seguir nessa missão de pastoral.
Muitas vezes não é fácil, é complicado [...] você não teve um motivo. $\mathrm{O}$ chamado em si já engloba tudo isso né [...] é você se comprometer com esse reino de Deus que a gente vive, mas do que nada, o que Deus nos pede" (E2).

Significa presença viva de Deus, significa eu poder é, repassar pra aquelas pessoas, as crianças, os jovens, os familiares, um pouco do amor de Jesus Cristo que eu vivo na minha família. Então eu saio né, um pouco de mim e me doou na missão de Jesus Cristo que é esse o nosso dever de cristão [...] a gente não pode ficar só pra gente mesmo né? (E4).

Eu já venho de várias pastorais [...] então é uma longa história de caminhadas pastorais... E a PASCOM ela surgiu quando [a cidade] teve a rádio. E é, iniciei o trabalho na rádio. Eu participava na rádio já, na época, como repórter e apresentador e quando a gente inaugurou a rádio a PASCOM foi instituída... Iniciou-se os trabalhos com a coordenação (E5).

É importante compreendermos que para um indivíduo fazer parte de uma coordenação em secretarias pastorais ou movimentos religiosos é necessário passar por toda uma formação educacional católica. Assim, inevitavelmente, todos os agentes organizacionais entrevistados, inclusive o padre, carregam consigo uma historicidade de pertencimento à organização, isto é, estão imersos na doutrina religiosa a anos compartilhando experiências e (re)elaborando significados que se fundem com as suas histórias de vida construídas na habitualidade (FRIEDLAND, 2014; ZAFIROVSKI, 2013). Essa característica de historicidade faz com que os agentes consolidem valores cristãos e organizacionais que perduram no tempo e reforçam suas identidades como agentes capazes de (re)construir padrões de comportamentos dinâmicos nas organizações. Além disso, dá contornos de 
legalidade e tradição, elementos que definem dois tipos de dominação, a saber, a tradicional e a legal (WEBER, 2015).

O fator da historicidade nos sentidos é delimitado por outros sentidos como a crença de missão, chamado, fraternidade, doação ao próximo etc., isto é, os sentidos estão conectados individual e coletivamente a partir de afinidades no credo religioso, formando a tessitura do social e dando unidade aos valores coletivos (FRIEDLAND, 2014; LIZARDO; STOLTZ, 2017). Esse fator de formação religiosa, pautado na vivência histórica dentro da doutrina católica, corrobora, também, para o exercício da liderança dentro da paróquia, consolidando e arraigando o sentimento de fé e crença a anos secularizados e profanados. Neste sentido, o líder carrega, independente de quem seja, aspectos de legalidade (condição para estar lá) e tradição, afastando, nestes relatos, aspectos voltados ao carisma ou a dominação carismática.

Embora o entendimento de "missão", "chamado", ou até mesmo "o doar-se" a uma santidade pareça transcender a racionalidade por partes dos entrevistados, trazendo à tona o misticismo religioso como formulador do sentido subjetivamente visado por esses agentes organizacionais (pontos de incompreensão receptiva), é justificável a reprodução da ação social guiada por esses sentidos porque são vistos não só como abstração da fé (relação subjetiva do indivíduo e a religiosidade), mas também como a solidez de princípios, convicções e ensinamentos católicos instituídos a partir do tempo de vivência ou contato com a organização. Como constatou Flausino, Medeiros e Valadão Júnior (2018), valores como fraternidade, compaixão, honestidade, respeito, "colocar-se no lugar do outro", aparentemente permeiam as práticas administrativas que estão associadas à moral cristã pregada pelas doutrinas religiosas tão peculiares e presentes nas formas de gestão nas organizações religiosas.
O próprio Weber (2015) reconhece um tipo específico de racionalidade valorativa substancial que responde por subsidiar um conjunto plural de ações, tais como essas que se apresenta a partir do olhar dos dominados e, também, do dominador. Portanto, é possível observamos que as ações dos agentes (padre e subordinados) estão carregadas de sentidos que, por vezes, assemelham-se, transformam-se, subvertem-se racionalmente (THIRY-CHERQUES, 2009) e guiam as ações organizacionais (SILVA, 2015). E nesse sentido, configura os valores básicos que constituem os sentidos e os modos de dominação no exercício da liderança organizacional.

\subsection{As Relações de Dominação e os Senti- dos Individuais e Compartilhados}

Os sentidos/valores da ação dos indivíduos são importantes para nosso estudo porque verificamos que eles permeiam as relações interpessoais dos agentes e são as bases do exercício da liderança como tipo singular de dominação organizacional, seja ao nível individual (pertencente a cada agente), seja ao nível coletivo (quando os agentes compartilham os sentidos social e organizacionalmente). Essa reflexão sustenta o argumento de que é vazio o entendimento da dominação sem entender os sentidos individuais e compartilhados que a caracteriza (WEBER, 2015).

A realidade organizacional apontada pelos relatos dos agentes expõe a existência do quadro de pastorais que se aproxima da teoria weberiana de dominação exercida a partir da racionalidade e da legalidade dos estatutos que delegam funções e responsabilidade.

Ela [a igreja] tem seu quadro assim, as pastorais sociais, as pastorais que domina mais o ponto fundamentação bíblica [...] Eu num... eu não abarcava sozinho pra coordenar e pra definir porque a gente se reúne, define as metas e eles aplicam [...] a gente se reúne cada mês pra avaliar 
e planejar. A gente faz a assembleia paroquial pra decidir o que nós vamos fazer durante aquele ano [..] tem aquelas reuniões, tem os encontros, as formações né, se não se perdia, num é? Você ficava perdido e não dava. Tem um planejamento (Padre). A gente já tem todo suporte, a gente tem reuniões preparatórias, assim, todo ano, a gente tem duas por anos e já é repassado tudo. Tem toda uma formação [...] a gente planeja antes, com um tempo de antecedência, né? Pra não dar tempo de fazer tudo [...] o que dá pra gente fazer durante o dia, a gente faz. Quando não dá pra cumprir, recomeça no outro dia (E1). Nós fazemos reuniões mensais. De uma a duas reuniões por mês. Nessas reuniões é feito um calendário do que vai realizado naquele mês. Por exemplo [...] escolhemos uma data ou um horário do qual seja acessível para a maioria. Então a gente senta num domingo à tarde e a gente debate o calendário do mês, quais são as atividades do mês [...] nós temos o calendário da igreja (E3).

Da liturgia a gente mensalmente, a gente se reúne e a gente define o que a gente vai fazer durante o mês [...] no TLC também não é diferente [...] dentro do nosso planejamento paroquial a gente tem a liberdade de definir o que a gente vai fazer naqueles meses [...] a gente atua como irmãos em Cristo, na fé, e se teve algum problema da situação de não ser cumprido aquele determinado... cronograma, então a gente faz a alteração e dá certo (E2).

Desses relatos, enxergamos uma dominação racional-legal caracterizada e exercida através do quadro de pastorais, movimentos religiosos e formações profissionais com as capacitações para os coordenadores. Sendo assim, o quadro de pastorais, o planejamento das ações e estabelecimentos de metas, as assembleias e o calendário paroquial relata- dos nos trechos das entrevistas acima, apresentam-se como mecanismos de gestão que legitimam a dominação racional-legal exercida pelo padre e líderes de pastorais que convergem os sentidos individuais, tornando-os coletivos, coabitando com diferentes racionalidades, buscando o equilíbrio e a estabilidade nas relações interpessoais dentro da organização (FRIEDLAND, 2014; WEBER, 2015; SILVA; CARVALHO, 2020).

No entanto, essa dominação racional-legal é caraterizada por um modo de organizar secular e, portanto, também histórico e tradicional. É uma dominação racional-legal que apresenta uma sobreposição de uma dominação tradicional sendo exercida pelo padre num equilíbrio entre o tradicional/contemporâneo, antigo/novo, estável/instável (ALVES, 2004). Mensalmente acontecem as assembleias nas quais são estabelecidos os planejamentos e metas para cada pastoral e movimento religioso. As metas colocadas no planejamento podem ser estabelecidas tanto a nível de atuação interna das pastorais, como também a nível paroquial em que envolve todas as pastorais e movimentos em prol das celebrações da igreja. Assim, constatamos uma forte autonomia de ação por parte dos agentes subordinados quanto à execução das metas traçadas, flexibilizando-as quanto à necessidade.

Em outras palavras, os agentes organizacionais além de deterem autonomia de ações, também apresentam forte características de ajustamento mútuo, isto é, ajudam-se diante das dificuldades ao colocar em prática os eventos religiosos. A cooperação entre os agentes ao organizarem as atividades paroquiais perpassa o campo da configuração organizacional formal e informal da organização, sendo a esta configuração organizacional, uma característica própria, institucionalizada pela forma de exercício de autoridade que o padre estabelece na organização. Existe uma 
forte intercomunicação entre as pastorais, em que os agentes organizacionais atuam não só em suas unidades pastorais, como também em caso de necessidade ajudam as demais pastorais a partir do caráter de urgência em que as atividades religiosas precisam ser realizadas.

Essa intercomunicação entre as pastorais demostra a existência de um sentido forte de cooperação e apoio entre os agentes das pastorais com o intuído de estar sempre em estado de missão e fé (CNBB, 2011). Essa unidade é percebida quando o padre trata deste assunto, indicando que "[...] todo trabalho com pessoa tem, mesmo que seja planejado, que seja avaliado é... ele tem falhas, porque se são dez pessoas, as vezes vai um ou dois falham, três ou quatro, aí deixa a lacuna né? Mas nem por isso a gente vai deixar de fazer". As regras importam e são válidas, mas compreendemos que a dominação racional-legal exercida pelo padre se estende a compreensão de uma administração burocrática em que os agentes apresentam forte autonomia e intercomunicação. Nesse ponto, a racionalidade valorativa substancial trabalha na elaboração de referências que servem de bases para as expectativas e união de valores que geram comportamentos organizacionais orientados por uma mesma ação coletiva, (re)transformando a organização a partir da ação e reação entre os agentes (ALVES, 2004; THIRY-CHERGUES, 2009; FRIEDLAND, 2014).

Além disso, compreendemos também que, a partir das falas dos entrevistados, muito do engajamento para a realização das atividades provém de um carisma presente.

Sem ter padre, a gente não tem como a fé e de outras coisas, né? Ele que é o ponto de partida. Então a importância é muito grande, a paróquia ter um padre pra orientar em tudo [...] a determinação [para trabalhar] dele. É uma pessoa de muita garra, determinação e coragem pra enfrentar muitas coisas que é a construção maior de nossa cidade, a nova matriz. Tá ali dentro... (E1).

Aqui a gente tem essa... monumento aqui sendo construído [a igreja matriz] com ajuda de todo mundo, mas tem a liderança dele. No então, eu acho que ele é um líder nato mesmo [...] eu acho que ele é empreendedor. Esse empreendedorismo [em construir] dele contagia muito as pessoas e faz com que a gente se espelhe nele também em relação a isso. Isso motiva a gente de qualquer forma (E2). $\mathrm{Eu}$ acho interessante nele é a capacidade, vamos dizer assim, de ser uma liderança. O padre, ele exerce uma liderança muito grande dentro da nossa igreja, uma liderança em todos os aspectos [...] em um munícipio que a maioria da população é da área rural e que não tem, vamos dizer assim, uma dinâmica regional muito grande conseguir a cinco anos está construindo uma igreja [...] está conseguindo levantar unicamente com doação das pessoas que são crentes na religião católica, isso mostra capacidade de uma liderança diante dos fiéis (E3).

Eu vejo assim ele tá sempre... ele é muito preocupado com as obras com a casa de Deus, ele é maravilhado em construção em deixar a casa de Deus o mais belo [...] a gente vem construindo a bela igreja, mas ele zela das capelas das nossas... do nosso munícipio do mais longínquo não é? zona rural até o mais próximo, todas muito bem cuidadas sempre com reformas, sempre zelando, além do zelo pelas pastorais, pelo povo de Deus né? (E4).

O padre carrega consigo um sentido de ação social pautado na crença e na fé católica, de trabalhar arduamente e a vontade de edificar os templos religiosos. Esses sentidos carregados pelo padre se conectam e guiam suas ações, e proporciona o exercício da dominação carismática, pois os demais agentes orga- 
nizacionais veem esses valores como preponderantes e característicos das ações do padre e por eles também guia suas ações dentro da organização. Em outras palavras, os agentes organizacionais (dominados) enxergam essa determinação em promover a construção abstrata e concreta da fé como ponto de referência para também guiar suas ações dentro da paróquia.

Assim, entendemos que a dominação carismática, exercida pelo padre, acontece através da afinidade de sentidos conectados que perpassou o campo da subjetividade individual, isto é, pertencente ao padre, transcendendo e encontrando âncoras nos sentidos compartilhados pelos demais agentes organizacionais. Essa afinidade de sentidos acontece uma vez que os sentidos que orientam a ação do padre são utilizados pelos seus dominados como também orientadores de suas ações organizacionais, numa espécie de acoplagem de significados.

Por assim dizer, além dos sentidos se conectarem subjetivamente no âmbito individual (padre), se conectam ainda no âmbito coletivo (padre e demais agentes) tecendo uma rede de sentidos subjetivamente visados que estimulam os indivíduos dominados a também trabalharem em favor da crença do sujeito-padre em atuar na direção estabelecida pelo sacerdote, que por sua vez também segue orientações hierarquizadas (WEBER, 2015). Logo, a tessitura organizacional formada a partir de uma associação de sentidos compartilhados legitima a dominação carismática exercida pelo padre numa autoridade que expressa os celebração de um direito à obediência (pelo dominador) e legitimado (pelo dominado) (SILVA; CARVALHO, 2020).

Desse modo, os sentidos que legitimam a dominação carismática exercida pelo padre encontram-se respaldo na crença que os agentes dominados atribuem de ser "o filho de Deus", "o bom pastor", atuante em prol da fé e espiritualidade cristã católica, o que reforça a crença dos dominados na conduta do dominador. Isto está estritamente relacionado ao que Weber (2015) denomina de dominação carismática genuína do cristianismo, ou seja, a crença em um ser que salva e/ou leva à vida eterna (CNBB, 2011), não necessariamente o próprio Cristo, mas uma vocação sacerdotal que se manifesta na conduta do padre em ser "empreendedor", "construtor", "líder nato" e demais adjetivos qualificadores da ação do padre. Ressalvamos, apenas, que apesar do padre carregar uma simbologia social católica, compreendemos que ele exerce uma dominação carismática por vias de um sentido intrínseco. Este sentido não é entendido pelo padre como uma benção divina e/ou um dom que detenha, uma vez que o sentido de trabalhar arduamente e edificar do padre que inicialmente orientava apenas suas ações sociais, por extrapolação, perpassou sua subjetividade e sua individualidade, tornando assim um valor coletivo como base do exercício da liderança que ele exerce (FRIEDLAND, 2014).

A existência dessa conexão de sentidos como esfera de valor coletiva que perpassa a individualidade e esclarecem os motivos pelos os quais os dominados se espelham e agem a partir do dominador e seus sentidos corrobora para legitimar, não só a dominação carismática, mas também a dominação tradicional e racional-legal exercida pelo padre, como um mútuo reforço. O que se aproxima do entendimento de Silva (2015) que entende a relação de dominação partir da perspectiva da sociologia reflexiva weberiana, compreendendo as relações sociais e organizacionais formadas mediante os sentidos subjetivos dos agentes.

A síntese das considerações teórico-empíricas levantadas durante a discussão dos resultados pode ser visualizada no quadro 1 que apresenta as unidades de sentido individuais 
(tanto do padre, quanto dos demais agentes organizacionais) e compartilhados por todos os agentes organizacionais aqui analisados. É possível observamos que as características que legitimam a relação de dominação exercida pelo padre sobre seus dominados através dos tipos puros de dominações de Weber (2015), apontando as unidades básicas de sentidos que constituem as esferas de valo- res individuais e coletivas. Essas unidades de sentidos são a base da dinâmica das relações de dominação dentro da organização, criando uma interconexão entre as ações, tornando-as coletivas num processo de rigidez/flexibilidade, disciplina/autonomia, centralização/descentralização organizacional (ALVES, 2004; FRIEDLAND, 2014).

Quadro 1. Unidades básicas de sentidos individuais que sustentam o exercício da dominação.

\begin{tabular}{|c|c|c|c|}
\hline \multicolumn{4}{|c|}{ Tipos de dominação em Weber } \\
\hline Sentidos & Tradicional & Carismática & Racional-legal \\
\hline $\begin{array}{l}\text { Individuais } \\
\text { (Padre) }\end{array}$ & $\begin{array}{l}\text { Sentidos } \\
\text { Compartilhados(Padre } \\
\text { e demais agentes) }\end{array}$ & $\begin{array}{l}\text { Sentidos } \\
\text { Compartilhados } \\
\text { (Padre e demais } \\
\text { agentes) }\end{array}$ & $\begin{array}{l}\text { Sentidos } \\
\text { Compartilhados } \\
\text { (Padre e demais } \\
\text { agentes) }\end{array}$ \\
\hline $\begin{array}{l}\text {-Vontade de } \\
\text { estudar; } \\
\text {-Garra e coragem } \\
\text { para trabalhar; } \\
\text {-Construir/ } \\
\text { edificar, }\end{array}$ & $\begin{array}{l}\text {-Preceitos religiosos } \\
\text { secularizados; } \\
\text {-Fé cristã católica; } \\
\text {-Práticas religiosas } \\
\text { (grupos institucionais); } \\
\text {-Historicidade (tempo } \\
\text { de contato com fé } \\
\text { católica); } \\
\text {-"Bom pastor" e "Filho } \\
\text { de Deus" (sentido forte } \\
\text { nos dominados). }\end{array}$ & $\begin{array}{l}\text {-Coragem de } \\
\text { trabalhar; } \\
\text {-Empreendedor } \\
\text { (construir); } \\
\text {-Liderança; } \\
\text {-Honestidade e } \\
\text { clareza; } \\
\text {-"Filho de Deus" } \\
\text { (sentido forte nos } \\
\text { dominados). }\end{array}$ & $\begin{array}{l}\text {-Forte autonomia de } \\
\text { ação; } \\
\text {-Liberdade para } \\
\text { reorganizar as tarefas; } \\
\text {-Cooperação e apoio; } \\
\text {-Intercomunicação } \\
\text { pastoral; } \\
\text {-Ajustamento mútuo }\end{array}$ \\
\hline
\end{tabular}

Fonte: Elaborado pelos Autores (2020).

Desta forma, os sentidos individuais e partilhados são as bases das relações de dominação exercida pelo padre e reconhecida pelos agentes organizacionais subordinados, promovendo ações coletivas de poder, autoridade e influência organizacional (SCHIERMER, 2016; LIZARDO; STOLTZ, 2017). É sabido também que o ordenamento organizacional se adapta ao carisma do dominador (SILVA; CARVALHO, 2012), flexibilizando, nesse caso, os mecanismos de uma dominação racional-legal exercida pelo padre, ressignificando sentidos individuais em compartilhados e instituindo uma autonomia organizacional e ajustamento mútuo preponderante para as ações dentro da organização. A constatar as bases que sustentam o exercício da liderança como tipo singular de dominação pelo padre como polifórmica, multifacetada, ou seja, híbrida quanto aos sentidos das ações organizacionais.

\section{Considerações Finais}

Neste estudo a nossa pretensão, como pesquisadores, foi explorar intersecção entre organização e religião, tencionando o elo entre poder, relações sociais e dominação como temáticas centrais de debate no campo de pesquisa da ciência da administração. Nesta perspectiva, nosso objetivo foi entender os 
sentidos individuais e compartilhados que caracterizam os modos de dominação existentes nas relações entre agentes numa organização religiosa. Para isto, partimos do pressuposto que percebe a liderança como um tipo singular de dominação, no sentido weberiano, exercido em relações sociais compreendidas mediante os sentidos individuais e coletivos dos agentes dentro das organizações.

Como resultado de pesquisa conseguimos compreender que a liderança exercida pelo padre se faz presente na realidade organizacional da paróquia de forma polifórmica, multifacetada, ou seja, hibrida, uma vez que esta dominação exercida mostrou ter traços característicos da dominação tradicional, racional-legal e carismática. A hibridez com as quais as tipologias de dominação weberiana se mostraram são resultados do contexto organizacional em que as relações sociais de trocas de sentido se dão e constituem esferas de valores organizacionais legitimadas. Assim, constatamos que os valores cristãos católicos históricos incorporados pelos agentes organizacionais (tanto dominador, quanto dominados) potencializam a ação coletiva dentro da organização e legitimam a liderança do padre.

Desse modo, entendemos que, a partir dos achados, a dominação se mostra mais potente em termos de estabilidade e manutenção do poder quando múltiplas bases para a ação estão ativas. No caso estudado, os valores que constituíram as bases da dominação tanto se assentaram na trajetória de vida do líder, base para o carisma, como também aspecto vinculados à tradição e legalidade. Um amálgama se mostra presente, em que os sentidos das ações socais do líder é sempre realçada como uma vitória - um exemplo - e os cursos, preparação e hierarquia da igreja como um terreno no qual a vitória é alcançada. Logo, percebemos como a dominação em múltiplas bases dá o contorno de uma cultura organizacional de servidão, de dominação, outrora já tipifica- da por Weber, mas ainda contemporaneamente percebida.

Ainda em tempo, compreendemos que a limitação da pesquisa se encontra na quantidade de entrevistados e na decisão metodológica de entrevistar apenas a linha subjacente central da administração paroquial - o que engloba as pastorais e a secretaria paroquial, uma vez que enxergamos a dominação exercida pelo padre não só diante dos coordenadores e secretários, mas também diante dos fiéis católicos existentes na comunidade em que a paroquia está situada. Além disso, sugerimos novas pesquisas voltadas para organizações vistas como centrais em nossa sociedade enquanto instituições de poder e dominação, como o exército, o parelho burocrático do Estado e outras organizações religiosas de diferentes doutrinas que não só a cristã católica.

\section{Referências}

ALVES, S. (2004). A multidimensionalidade nas organizações empresariais: proposta de um modelo analítico. Revista de Administração Contemporânea, v. 8, n. 2, p. 71-93, 2004. https://doi.org/10.1590/ $\underline{\mathrm{S} 1415-65552004000200005}$

ARAUTOS DO EVANGELHO. Atividades do ano de 2004: Recife - PE, 2004. Recuperado de: http://mediablogs.arautos.org/recife/files/2017/07/ Relat\%C3\%B3rio-2004.pdf.

ARONOVITCH, H. Interpreting Weber's Ideal-Types. Philosophy of the Social Sciences, v. 42, n. 3, p. 356369, 2012. https://doi.org/10.1177/0048393111408779 AVENTURA PASSIRA. Blog Aventura Passira: Paróquia de Passira dá a Largada na construção de Nova Matriz, 2012. Recuperado de: http:// aventurapassira.blogspot.com/2012/01/paroquia-depassira-da-largada-na.html.

BAUER, M. W. Análise de conteúdo clássica: uma revisão. In: BAUER, M. W.; GASKELL, G. (Org.). Pesquisa qualitativa com texto, imagem e som: um manual prático. Petrópolis, RJ: Vozes, 2002.

CENCI, R.; FILIPPIM, E. S. Atração e permanência de pessoas em instituições religiosas católicas: o peso dos contornos institucionais. Cadernos EBAPE.BR, v. 15, n. 1, p. $152-168,2017$. https://doi.org/10.1590/1679395149075 .

CNBB, Conferência Nacional dos Bispos do Brasil. Projeto Nacional de Evangelização: O Brasil na Missão Continental. Brasília, Edições CNBB, 2008.

CNBB, Conferência Nacional dos Bispos do Brasil. 
Diretrizes Gerais da Ação Evangelizadora da Igreja no Brasil: 2011-2015. Brasília, Edições CNBB, 2011. CORRÊA, V.; VALE, G. Estrutura Social e Empreendedorismo Religioso: uma associação teórica. Revista de Administração IMED, v. 7, n. 2, p. 308322, 2017. https://doi.org/10.18256/2237-7956.2017. v7i2.1684.

CRESWELL, J. W.; MILLER, D. L. Determining Validity in Qualitative Inquiry, Theory Into Practice, v. 39, n. 3, 124-130, 2000.

DIÁRIO POLÍTICO. Diário Político de Feira Nova: Em Passira, Padre Antônio Maria será a atração da Festa de Nossa Senhora da Conceição, 2013. Recuperado de: https://diriopolitcodefeiranova. blogspot.com $/$ search?q=Par\%C3\%B3quia+Passira.

DYCK, B.; WIEBE, E. (2012). Salvation, theology and organizational practices across the centuries. Organization, v. 19, n. 3, p. 299-324, 2012. https:// doi.org/10.1177/1350508412437073.

ENOQUE, A.; BORGES, J.; BORGES, A. Representações do lucro no comércio de artigos religiosos: interpretações do sagrado e do profano no cotidiano das organizações. Revista Eletrônica de Ciência Administrativa, v. 13, n. 3, p. 372-392, 2014. https://doi.org/10.21529/RECADM.2014024

FLAUSINO, V. S.; MEDEIROS, C. R. O.; VALADÃO JÚNIOR, V. M. Poder e Religião: a Doutrina Espírita no Modo de Pensar dos Gestores de Uberaba/MG. Revista ADM.MADE, v. 22, n. 1, p. 58-76, 2018. http://dx.doi. org/10.21714/2237-51392018v22n1p058076

FLICK, U. Introdução à metodologia de pesquisa: um guia para iniciantes. Penso Editora, 2012.

FRIEDLAND, R. "Divine institution: Max Weber's value spheres and institutional theory", Religion and Organization Theory. Research in the Sociology of Organizations, v. 41, p. 217-258, 2014.

FRIEDLAND, R. The Constitution of Religious Political Violence: Institution, Culture, and Power. The Oxford Handbook of Cultural Sociology, p. 1-49, 2017. GONÇALVES, J. C. S.; SERRA, A. R. C.; COSTA, C. E. S. (2007). A empresarização do sagrado: um estudo sobre a estruturação de igrejas protestantes brasileiras. Revista Eletrônica de Ciência Administrativa, v. 6, n. 2, p. 1-14, 2007. DOI: 10.5329/ RECADM.20070602010

LIMA, A. S. Gestão de pessoas em organizações religiosas: o caso da Igreja Presbiteriana do Brasil (Dissertação de Mestrado). Universidade Presbiteriana Mackenzie, São Paulo, SP, Brasil, 2016.

LIZARDO, O.; STOLTZ, D. S. Max Weber's ideal versus material interest distinction revisited. European Journal of Social Theory, v. 21, n. 1, p. 3-21, 2018. https://doi.org/10.1177/1368431017710906

MERRIAM, S. B. Qualitative Research: A guide to design and interpretation. San Francisco: JosseyBass. 2009.
PAIVA, F., JR.; LEÃO, A.; MELLO, S. Validade e confiabilidade na pesquisa qualitativa em administração. Revista de Ciências da Administração, v. 13, n. 31, p. 190-209, 2011. https://doi.org/10.5007/2175$\underline{8077.2011 \mathrm{v} 13 \mathrm{n} 31 \mathrm{p} 190}$

RAMOS, I. O. R., Jr., et al. Liderança Organizacional: um levantamento bibliográfico. Universitas Gestão e TI, v. 6, n. 2, p. 87-95, 2016.

SCHIERMER, B. Weber's listening: Nonpurposive figures in Weber. Journal of Classical Sociology, v. 16, n. 2, p. 137-154, 2016. https://doi. org/10.1177/1468795X15624188.

SERAFIM, M. C.; ALPERSTEDT, G. D. As organizações religiosas e suas relações: Uma análise a partir da teoria dos stakeholders. Revista de Negócios, v. 17, n. 2, p. 21-40, 2012. http://dx.doi. org/10.7867/1980-4431.2012v17n2p53-71.

SILVA, A. S. A liderança como relação social: uma proposta de abordagem interpretativa a partir da teria e das estruturas típicas de dominação weberianas. (Tese de Doutorado). Programa de PósGraduação em Administração. Pontifica Universidade Católica de Minas Gerais. Belo Horizonte, MG, Brasil, 2015.

SILVA, A. S.; CARVALHO, A.; NETO. Uma contribuição ao estudo da liderança sob a ótica weberiana de dominação carismática. Revista de Administração Mackenzie, v. 13, n. 6, p. 20-47, 2012. https://doi.org/10.1590/S1678-69712012000600003.

SILVA, A. S., \& CARVALHO, A., NETO. Uma análise weberiana da gestação de estruturas de dominação em sindicatos. Revista de Administração da UFSM, v. 13, n. 1, p. 01-19, 2020. doi: https://doi. org/10.5902/1983465928977

SOUZA, J. A. G. et. al. A distância da Academia para o Mundo das Organizações: Analisando a pesquisa e o ensino em Administração a partir do perfil dos pesquisadores do EnANPAD. Revista de Administração da FATEA, 16, 7-30, 2018.

THIRY-CHERQUES, H. R. Max Weber: o processo de racionalização e o desencantamento do trabalho nas organizações contemporâneas. Revista de Administração Pública, p. 43, v. 4, p. 897-918, 2009. https://doi.org/10.1590/S0034-76122009000400007.

TRACEY, P. Religion and Organization: A Critical Review of Current Trends and Future Directions. Academy of Management ANNALS, n. 6, p. 87-134, 2012. https://doi.org/10.5465/19416520.2012.660761. WEBER, M. A ética protestante e o espírito do capitalismo. São Paulo: Pioneira, 1996.

WEBER, M. Economia e Sociedade: fundamentos da sociologia compreensiva. Brasília: Editora Universidade de Brasília, 2015.

ZAFIROVSKI, M. The sociological core vs. the historical component of the weber thesis: Some deviant cases revisited. Current Perspectives in Social Theory, v. 31, p. 75-128, 2013. 